\title{
Claims of Near-Death Experiences, Gestalt Resistance Processes, and Measures of Optimal Functioning
}

\author{
Kevin P. Prosnick, Ph.D. \\ John Carroll University
}

\begin{abstract}
The present study investigated the relationship between claims of near-death experiences (NDEs) and measures of self-actualization, Gestalt resistance processes, transfluence, mystical experiences, and claims of peak life experiences in a sample of 155 individuals. As hypothesized, I found significant positive correlations between the claims of NDEs and transfluence and mystical experiences. I found no significant correlations between claims of NDEs and the seven Gestalt resistances, suggesting that NDErs are neither more nor less resistant than nonNDErs. I also found no significant relationship between claims of NDEs and self-actualization or claims of peak life experiences.
\end{abstract}

Near-death experiences (NDEs) have been the focus of abundant research over the past 30 years, much of it focused on the phenomenological reports of the individual reporting the NDE (Greyson and Bush, 1992; Ring, 1980, 1984, 1992). Very little empirical data have been reported regarding the relationship between claims of near-death experiences, self-actualization, Gestalt resistances, transfluence, mystical experiences, and claims of peak life experiences. Gestalt resistances can be understood to be defensive styles or strategies that become problematic when they are overused or utilized without awareness (Perls, Hefferline, and Goodman, 1951/1977). Transfluence is a measure of transpersonal experiences.

The purpose of this study was to investigate the relationship between claims of near-death experiences and measures of the above-mentioned constructs. I hypothesized that claims of near-death experiences would

Kevin P. Prosnick, Ph.D., is a Certified Transpersonal Psychologist, and an Adjunct Professor of Counseling and Human Services at John Carroll University, Cleveland, $\mathrm{OH}$. Reprint requests should be addressed to Dr. Prosnick at 6384 Peck Road, Ravenna, OH 44266 . 
be negatively related to Gestalt resistance scores as measured by a Gestalt questionnaire, and positively related to self-actualization, transfluence, mystical experiences, and claims of peak life experience. In other words, I expected individuals claiming to have had an NDE to possess low Gestalt resistances and vice versa. Likewise, I expected individuals claiming an NDE to report high self-actualization, transfluence, mystical experiences, and claims of peak life experience.

\section{Method}

\section{Participants}

A total of 155 individuals participated in the study. The nonprobability convenience sample was composed of 54 males and 101 females with ages ranging from 18 to 78 . The majority of the sample was drawn from education and counseling students from three Ohio universities, with the remainder drawn from private sector organizations in the area. All 155 individuals were used in the correlations between claim of an NDE with the measures of Gestalt resistances, transfluence, and claim of peak life experience; while only 109 subjects completed the measure of self-actualization, 152 the measure of mystical experiences, and 119 the Short Lie scale, which was composed of three items from the MMPI-2 Lie scale and was administered as a check on social desirability.

\section{Instruments}

Claims of near-death experiences was measured by a single question- "Have you ever had a Near Death Experience?" - to which subjects could answer "yes" or "no."

Self-actualization was measured by the Short Index of Self-Actualization (SISA) (Jones and Crandall, 1986). I use a 5-point Likert-type scale, with responses ranging from 1 ("I Strongly Agree with this Statement") to 5 ("I Strongly Disagree with this Statement") for each of the 15 items. Alvin Jones and Rick Crandall (1986) reported an acceptable coefficient alpha (.65) and a 12-day interval test-retest reliability (.69) for the SISA using a 4-point Likert format.

The SISA was a modification of the first instrument to measure of self-actualization, the Personal Orientation Inventory (POI) (Shostrom, 1963), and is significantly correlated with the POI (Jones and Crandall, 1986). The initial validation study of the SISA found significant differences between persons nominated as self-actualizing and those nominated as non-self-actualizing (Jones and Crandall, 1986). The SISA 
significantly correlated in expected directions with self-esteem and neuroticism (Jones and Crandall, 1986), boredom proneness (McLeod and Vodanovich, 1991), perfectionism (Flett, Hewitt, Blankstein, and Mosher, 1991) and creativity (Runco, Ebersole, and Mraz, 1991).

The Gestalt Contact Styles Questionnaire-Revised (GCSQ-R; Woldt and Kepner, 1993) was selected to measure the six traditional Gestalt resistances: confluence, desensitization, introjection, projection, retroflection, and deflection. Confluence is the process whereby the boundaries between self and environment become undifferentiated to the point where awareness of self is lost in the environment, for example, in a group or another person. Desensitization is the process of blocking sensory contact or hindering sensory information from being recognized. Introjection is the process of passively accepting and incorporating material, such as rules or attitudes, from the environment without examining, challenging, or integrating that material. Projection is the process of disowning personally objectionable material, such as thoughts or feelings, and assigning this material to the environment, for example, to other people or objects. Retroflection is the process of thwarting need fulfillment by redirecting impulses away from the environment and back toward the self, either by doing to oneself what one would like to do to others, such as pounding one's fist against one's forehead, or by doing to oneself what one would like others to do, for example, gently stroking one's forehead. Deflection is the process of avoiding or reducing the intensity of contact through various behaviors, for example, changing topics or using humor to relieve tension.

The 100 items on the GCSQ-R were responded to on the same 5-point Likert-type scale presented above. Robert Hoopingarner (1987) reported a total-score test-retest reliability of .83 for a 2 - to 4 -week interval, with all six resistance scales test-retest reliability exceeding .70 .

The six resistance scales were derived through factor analysis (Woldt and Kepner, 1993). A number of empirical studies supported the construct validity of the resistance scales (Prosnick, 1996). The GCSQ-R is the only extant measure of Gestalt resistance processes with acceptable psychometric properties.

The seventh Gestalt resistance of egotism was measured by the egotism scale. Egotism is the process by which a person mentally separates from his or her experience and becomes a spectator of, or commentator on, that experience. I developed this egotism scale through factor analysis and reported an acceptable coefficient alpha of .76 (Prosnick, 1996). The egotism scale exhibited convergent validity with a measure of ego rigidity and discriminant validity with a measure of selftranscendence (Prosnick, 1996). 
Transfluence is a measure of transpersonal experiences created through factor analysis (Prosnick, 1996). The types of experiences included on the Transfluence Scale include seeing auras and traveling out of body. I reported a high coefficient alpha of .90 for this scale which exhibited convergent validity with the Mysticism Scale (Prosnick, 1996).

Reported mystical experiences were measured by the Mysticism Scale (M Scale) (Hood, 1975). The Mysticism Scale is scored in a 5-point Likert-type format, with a range from 32 points measuring least mystical to 160 assessing most mystical, derived from factor analysis (Hood, 1975). A recent study by Ralph Hood, Ronald Morris, and Paul Watson (1993) established a three-factor structure for the M scale compatible with the conceptual work of Walter Stace (1960), from whom the scale items were initially developed. The $\mathrm{M}$ scale is the most frequently cited measure of self-transcendence, and is the most widely used and the only psychometrically acceptable instrument available for operationalized reporting of mystical experience.

Reliability for the $M$ scale was in acceptable ranges: Cronbach's alpha coefficient of internal consistency was .92 (Stifler, Greer, Sneck, and Dovenmuehle, 1993). Correlational findings support the construct validity of the $M$ scale. Convergent validity was indicated by significant positive correlations between the $M$ scale and measures of intrinsic religious orientation, intense religious or spiritual experience, and openness to experience. The Intrinsic Religious Motivation Scale (Hoge, 1972), Religious Experience Episodes Measure (Hood, 1970), and Ego Permissiveness Scale (Taft, 1970) each correlated positively with M scale scores (Hood, 1975).

Claim of peak life experience was measured by a single question"Have you ever had a 'Peak' or highly unusual, positive life experience?" - to which subjects could answer "yes" or "no." As a check on social desirability, three items from the MMPI-2 Lie scale were administered.

\section{Level of Significance}

In this exploratory study, I chose to take a bigger risk of making a type I error, so that possible relationships for further investigation could be identified. Therefore, alpha was set at $p=.20$. Bonferroni's inequality was used to correct for multiple simultaneous correlational tests (Grove and Andreasen, 1982); applying that to the 12 variables in this set of data, the required level of significance for each individual statistical test was set at $\mathbf{p}=.017$. 


\section{Procedure}

All participants were given a questionnaire including the above measures, and were given as much time as needed to complete it. All questionnaires listed the scales in identical order, since it has been empirically demonstrated that scale order has little affect on interscale correlations (Spector and Michaels, 1983).

\section{Results}

The number of study participants who responded "yes" to the question about having had a near-death experience was 25 ( 16 percent); while 88 participants ( 58 percent) responded "yes" to the question about having had a peak life experience.

Table 1 presents the possible range of scores, mean, standard deviation, and coefficient alphas for all study scales, while Table 2 presents zero-order correlations between claiming to have had an NDE and the other study variables. As can be seen, claiming to have had an NDE was significantly correlated with higher scores on the Transfluence Scale $(\mathrm{r}=.21)$ and the Mysticism Scale $(\mathrm{r}=.23)$. There were no significant relationships between the claim of having had NDE and the other study variables. There were no significant correlations between the Short Lie

Table 1

Statistics of Study Scales

\begin{tabular}{llrrr}
\hline & $\begin{array}{c}\text { Possible } \\
\text { Range }\end{array}$ & Mean & \multicolumn{1}{c}{$S$ D } & $\begin{array}{c}\text { Internal } \\
\text { Consistency } \\
\text { (Alpha) }\end{array}$ \\
\hline SISA & $15-75$ & 51.95 & 5.27 & .67 \\
Confluence & $22-110$ & 66.55 & 7.38 & .59 \\
Desensitization & $12-60$ & 33.65 & 5.57 & .58 \\
Introjection & $23-115$ & 75.61 & 6.16 & .35 \\
Projection & $27-135$ & 70.12 & 11.92 & .85 \\
Retroflection & $43-215$ & 109.08 & 15.81 & .85 \\
Deflection & $43-215$ & 102.79 & 15.42 & .85 \\
Egotism & $11-55$ & 27.01 & 5.48 & .71 \\
Transfluence & $18-90$ & 50.90 & 13.20 & .90 \\
M Scale & $32-160$ & 99.26 & 22.92 & .96 \\
Short Lie & $3-15$ & 6.43 & 1.65 & .17 \\
\hline
\end{tabular}


Table 2

Correlations Between Claim of Having Had an NDE, Short Lie Scale, and the Study Variables

\begin{tabular}{lrr}
\hline Variable & NDE & Short Lie \\
\hline Self-actualization & .05 & .07 \\
Confluence & -.15 & -.08 \\
Desensitization & .12 & -.07 \\
Introjection & -.15 & .21 \\
Projection & .01 & -.13 \\
Retroflection & .01 & -.06 \\
Deflection & .00 & -.11 \\
Egotism & .01 & -.05 \\
Transfluence & $.21^{*}$ & -.11 \\
Peak Life Experience & .17 & .06 \\
Mysticism Scale & $.23^{*}$ & -.17 \\
Short Lie & .11 & 1.00 \\
\hline
\end{tabular}

Scale and any study variables, which suggests that a social desirability response set did not affect these data.

\section{Discussion}

This study supports the contention that individuals claiming to have had an NDE also report high rates of transfluence and mystical experiences. These findings indicate that persons claiming an NDE have had more transpersonal experiences than have the nonNDE sample. The study design did not permit distinguishing between transpersonal experiences that occurred prior to or after the NDE. Future research could determine whether "transpersonal experiencers" are predisposed to have NDEs, or whether NDEs make people more inclined to have transpersonal experiences.

No significant correlations were found between claim of NDEs and the seven Gestalt resistances. Thus NDErs as a group were neither more nor less resistant than the nonNDErs. No significant relationship was found between claim of an NDE and claim of a peak life experience. 
Additionally, no significant relationship was found between claim of an NDE and self-actualization. Bruce Greyson (1992) reported a similar lack of significant relationship between actualization and occurrence or depth of NDEs.

A methodological limitation of the present study is that individuals claiming to be NDErs were identified neither by a standardized instrument nor by an interview, but rather a single "yes" or "no" question. Thus, some individuals may have broadly interpreted this question to include physical near-death encounters that may not have included the components of the psychospiritual NDE. This limitation notwithstanding, the results of this study are logically consistent with previous neardeath investigations (Ring, 1980, 1984, 1992).

A future study could correct for the above limitation by utilizing a psychometrically sound instrument to identify the NDErs, like the one presented by Greyson (1983). This group could then be correlated with the same or similar measures chosen for this study. It may also be beneficial for future research to replicate the present study with other samples to assess the generalizability of the findings.

Future studies could also assess the causal nature of the relationship between claim of an NDE and transpersonal experiences, that is, transfluence and mystical experiences. For instance, does an NDE lead to increased transpersonal experiences, does high capacity for selftranscendence lead to greater likelihood of claiming an NDE, or is there a reciprocal relationship? It is also possible that other variables might control the relationship between claim of an NDE and transpersonal experiences.

\section{References}

Flett, G. L., Hewitt, P. L., Blankstein, K. R., and Mosher, S. W. (1991). Perfectionism, selfactualization, and personal adjustment. Journal of Social Behavior and Personality, 6 , $147-160$.

Greyson, B. (1983). The Near-Death Experience Scale: Construction, reliability, and validity. Journal of Nervous and Mental Disease, 171, 369-375.

Greyson, B. (1992). Reduced death threat in near-death experiencers. Death Studies, 16 , 523-536.

Greyson, B., and Bush, N. E. (1992). Distressing near-death experiences. Psychiatry, 55, 95-110.

Grove, W. M., and Andreasen, N. C. (1982). Simultaneous tests of many hypotheses in exploratory research. Journal of Nervous and Mental Disease, 170, 3-8.

Hoge, D. R. (1972). A validated intrinsic religious motivation scale. Journal for the Scientific Study of Religion, 11, 369-376. 
Hood, R. (1970). Religious orientation and the report of religious experience. Journal for the Scientific Study of Religion, 9(4), 285-291.

Hood, R. (1975). The construction and preliminary validation of a measure of reported mystical experience. Journal for the Scientific Study of Religion, 14, $29-41$.

Hood, R., Morris, R., and Watson, P. (1993). Further factor analysis of Hood's Mysticism Scale. Psychological Reports, 73, 1176-1178.

Hoopingarner, R. (1987). A reliability study of the Gestalt Contact Styles QuestionnaireRevised (GCSQ-R). Unpublished master's thesis, Kent State University, Kent, Ohio.

Jones, A., and Crandall, R. (1986). Validation of a short index of self-actualization. Personality and Social Psychology Bulletin, 12, 63-73.

McLeod, C. R., and Vodanovich, S. J. (1991). The relationship between self-actualization and boredom proneness. Journal of Social Behavior and Personality, 6, 137-146.

Perls, F., Hefferline, R., and Goodman, P. (1977). Gestalt therapy: Excitement and growth in the human personality. New York: Bantam. (Original work published 1951)

Prosnick, K. P. (1996). Final contact and beyond in Gestalt therapy theory and transpersonal research: A factor analytic study of egotism and transfluence. Unpublished doctoral dissertation, Kent State University, Kent, OH. (Dissertation Abstracts International, 57-12, A5064; UMI No. AAI9716995)

Ring, K. (1980). Life at death: A scientific investigation of the near-death experience. New York: Coward, McCann, and Geoghegan.

Ring, K. (1984). Heading toward omega: In search of the meaning of the near-death experience. New York: William Morrow.

Ring, K. (1992). The Omega Project: Near-death experiences, UFO encounters, and mind at large. New York: William Morrow.

Runco, M. A., Ebersole, P., and Mraz, W. (1991). Creativity and self-actualization. Journal of Social Behavior and Personality, 6, 161-167.

Shostrom, E. (1963). Personal Orientation Inventory. San Diego, CA: Educational and Industrial Testing Service.

Spector, P. E., and Michaels, C. E. (1983). A note on item order as an artifact in organizational surveys. Journal of Occupational Psychology, 56, 35-36.

Stace, W. T. (1960). Mysticism and philosophy. Philadelphia: Lippincott.

Stifler, K., Greer, J., Sneck, W. and Dovenmuehle, R. (1993). An empirical investigation of the discriminability of reported mystical experiences among religious contemplatives, psychotic inpatients, and normal adults. Journal for the Scientific Study of Religion, $32,366-372$.

Taft, R. (1970). The measurement of the dimensions of ego permissiveness. Personality: An International Journal, 1, 163-184.

Woldt, A., and Kepner, J. (1993). Gestalt Contact Styles Questionnaire-Revised (GCSQ-R): Item composition of factors I-VI. In A. D. Carden, A process typology of men who have abused their female intimate partners: Implications for intervention based on the Gestalt therapy theory of resistance process (pp. 239-249). Unpublished doctoral dissertation, Kent State University, Kent, OH. (Dissertation Abstracts International, 54-09, B4910; UMI No. AAI9405921) 